\title{
O SUS ainda pulsa (firme e forte): quando a vanguarda vem da "periferia"
}

PINHEIRO, R.; SILVEIRA, R.; LOFEGO, J.; LEAL, O. e GUIZARDI, F.L. (Orgs.).

\section{Apoiando a Gestão do SUS em Rio Branco-Acre:}

a estratégia da incubadora de integralidade no desenvolvimento institucional local.

Rio de Janeiro: CEPESC, 2013. 338p.

\section{$I^{1}$ André Luis de Oliveira Mendonça | \\ 1 Professor adjunto, Instituto de Medicina Social da UERJ. Endereço eletrônico: andremendonca@ims.uerj.br}

O livro Apoiando a Gestão do SUS em Rio Branco-Acre: a estratégia da incubadora de integralidade no desenvolvimento institucional local, organizado por Roseni Pinheiro et al., veio à luz no momento especial de comemoração pelos 25 anos do SUS, ocasião propícia para a realização, dentre outras empreitadas, de um balanço geral acerca de seus avanços, problemas e novos desafios. Outrossim, a efeméride de um quarto de século de existência também deveria nos instar a tentar dar mais visibilidade às experiências exitosas que foram alcançadas até aqui, para que estas possam nos servir como estímulos prestimosos para a renovação da busca sã, por meio de uma luta coletiva ininterrupta, por um sistema de saúde universal, igualitário, emancipador e solidário.

Fruto de uma pesquisa-extensão de grande porte denominada "Apoio ao desenvolvimento institucional do SUS em Rio Branco" (cujo objetivo precípuo consistiu em "[...] inaugurar um dispositivo germinador de estudos voltados para a relação entre áreas programáticas estratégicas e a construção de práticas de integralidade no SUS [...]", como salientam na introdução duas das organizadoras do livro), inserida no interior da Rede Multicêntrica de Pesquisa Incubadoras de Integralidade, liderada pelo Laboratório de Pesquisas sobre Práticas de Integralidade em Saúde (Lappis), o livro é um exemplo emblemático de que o SUS, contrariando os arautos de más notícias, está vivo como nunca antes - basta manter os olhos abertos e atentos para as experiências inovadoras que acontecem fora do eixo das grandes cidades. 
A obra está dividida em três partes: na primeira, Trajetórias programáticas em saúde: leituras reflexivas sobre a construção da integralidade na luta por direitos, estão presentes relatos sobre a construção da pesquisa realizada na Secretaria Municipal de Saúde de Rio Branco (SEMSA); na segunda, com o título de Trajetória da Incubadora da Integralidade na Amazônia Legal: memórias de educação permanente no desenvolvimento institucional no SUS de Rio Branco, Acre, discute-se a experiência de formação desenvolvida no Curso de Desenvolvimento Gerencial (CDG-SUS Rio Branco); a terceira, como o próprio título Olhares Constitutivos do Desenvolvimento Institucional no SUS já o indica, discorre sobre outras visōes focadas em experiências inovadoras. A seguir, um pequeno resumo do conteúdo dos capítulos em ordem ligeiramente diferente da encontrada no livro, fechando com uma rápida conclusão inspirada no sentimento de revigoramento que sua leitura despertou em mim.

Como a primeira parte do livro trata dos aspectos institucionais da SEMSA, julgo que vale a pena começar mencionando o capítulo que narra a longa história de luta até sua criação. Abrindo a segunda parte do livro, no capítulo intitulado "O percurso da saúde pública em Rio Branco: de sede do Departamento do Alto Acre à capital do Estado do Acre”, Osvaldo Leal, Eufrasia Cadorin, Douglas Angel, Maurício Rebouças e Adônidas Rodrigues Jr. relatam feitos e fatos que vão desde a expedição científica liderada por Oswaldo Cruz em 1912, quando a população de Rio Branco era de cerca de dois mil habitantes, até a atual configuração da Secretaria Municipal de Saúde de Rio Branco, que conta com mais profissionais do que a população de cem anos atrás. Com ênfase justamente na SEMSA (criada em 1988, através da Lei no 770, de 26 de dezembro), mais precisamente na complexidade cada vez maior do seu organograma (com a criação de novas unidades e departamentos, ao longo do tempo), chama-se a atenção para um processo permanente de lutas em direção a uma gestão mais democrática e compartilhada, na qual há, em que pesem os obstáculos persistentes, preocupação crescente com a qualificação e valorização dos trabalhadores, bem como com a participação direta da população nos rumos da gestão.

Exemplo específico concreto dessa história de lutas no município de Rio Branco em prol da saúde está narrado no segundo capítulo da primeira parte. Como é sugerido pelo próprio título, "Trajetos, trajetórias e caminhos para a garantia de direito na saúde no município de Rio Branco, Acre”, Felipe Rangel 
de Souza Machado, Francini Lube Guizard e Alda Lacerda relatam o processo

de construção do direito à saúde em Rio Branco, sob a perspectiva do direito como mediação de transformações sociais. Em contraposição à concepção do direito como uma instância meramente técnica, neutra e apolítica (concepção formalista), os autores ancoram-se na ideia de justiça no sentido igualitário defendido por Amartya Sen, de modo a sustentar a importância do papel dos trabalhadores na implementação efetiva dos direitos relativos à saúde. A partir de cinco experiências locais - tematizadas sob a égide da noção de sistema de dádivas", de reconhecimento social do filósofo frankfurtiano Axel Honneth e de equidade de Amarthya Sen -, os autores sublinham, sem deixar de chamar a atenção para os fatores que ainda atuam como obstáculos, os aspectos positivos nessa luta pela concretização de direitos: respeito e solidariedade com um grupo social marginalizado (evangélicos); inclusão social de uma menina, que até então não sorria, por meio da restauração dos seus dentes; tentativa de priorizar aqueles que apresentam maiores dificuldades de acessibilidade, especialmente os que vivem no interior das florestas e nas zonas rurais mais afastadas; relativa ampliação da participação social por meio do Conselho de Saúde; e diminuiçãoo das diferenças religiosas por meio de um instituto ecumênico.

Nessa mesma linha de argumentação em favor da conquista de direitos de populações e grupos mais vulneráveis, Ana Lucia de Moura Pontes, Sérgio Rego e Luiza Garnelo discutem o modelo de atenção da Política Nacional de Atenção à Saúde dos Povos Indígenas (Pnaspi) e sua difícil operacionalização nos 34 Distritos Sanitários Especiais Indígenas do Alto Rio Negro (DSEIRN) no penúltimo capítulo do livro, intitulado "Formulação e implementação de modelos de atenção à saúde para as populaçôes indígenas: contribuições para o fortalecimento da sensibilidade cultural e da diferenciação das ações de saúde”.

Ainda sobre os aspectos institucionais da SEMSA, mais precisamente da integralidade institucional, o capítulo de abertura do livro, "As políticas específicas no SUS e o desafio de construção da integralidade: uma análise das relações institucionais no desenvolvimento do trabalho das áreas técnicas da Secretaria Municipal de Saúde de Rio Branco, Acre”, de autoria de Francini Lube Guizardi, Felipe Rangel de Souza Machado e Alda Lacerda, aborda a questão dos avanços e desafios no que tange à interação entre as diversas áreas técnicas que compõem a SEMSA - nomeadamente, o Departamento de Ações Programáticas Estratégicas 
(DAPES), responsável pela articulação de vários programas específicos (de Saúde da Criança à Saúde do Idoso, passando por Saúde Mental e Saúde da Mulher) -, tendo como mote a superação dos dois padrões institucionais tradicionalmente hegemônicos na saúde: fragmentação e centralização normativa. Dentre outros resultados assaz significativos obtidos pelos autores, eles elencam achados que nos trazem uma esperança encorajadora: malgrado a normatividade vertical e a fragmentação institucional ainda predominarem nas relações das áreas técnicas com o Ministério da Saúde, a SEMSA, os profissionais de saúde e os representantes dos usuários, o reconhecimento de que enfrentam dificuldades e problemas similares tem levado, por exemplo, gerentes de áreas técnicas e do Ministério da Saúde a constituírem laços de solidariedade; ou iniciativas como o Programa de Saúde da Comunidade tem favorecido maior integração com a população.

Em "O trabalho como mediação na constituição de redes no cenário das áreas programáticas em saúde do município de Rio Branco” (terceiro capítulo da primeira parte), os mesmos autores examinam novamente a questão das relaçôes institucionais, sendo que sob a ótica do trabalho em equipe como mediação na formação de redes. Partindo de referenciais do campo da saúde do trabalhador (e.g.: ideia de complementaridade entre trabalho prescrito e trabalho real), dentre outros, os autores trabalham três dimensões da mediação em rede a partir do material empírico: parceria entre as áreas técnicas, reconhecimento social e caráter formativo das redes. Visando à superação dos obstáculos observados, propõem-se, dentre outras estratégias, melhorar o fluxo de informações das áreas técnicas com os movimentos sociais, criação de uma gestão conjunta e direta com a comunidade e a prática de um planejamento e atuação colaborativa entre as áreas técnicas.

Com relação aos trabalhos atrelados à experiência do CDG-SUS Rio Branco, faz-se mister iniciar aludindo ao texto que rememora a história da Política Nacional de Humanização (PNH), referencial institucional do curso. Política essa sobre a qual eu poderia dizer, inspirado em Lévinas, que se preocupa em humanizar o outro homem. Como o próprio título sugere, no capítulo "Avanços e desafios da Política Nacional de Humanização no contexto local: uma história construída coletivamente" (sexto texto da segunda parte), Ana Flávia da Costa Nobre Angel, Maurício Rebouças, Emelym Daniela Tonelly, Tuianne Camboim Morais e Viviane Paza fazem um balanço do processo de construção da $\mathrm{PNH}$ 
em Rio Branco. Além de fornecerem uma boa síntese dos valores subjacentes ao projeto de humanização da saúde (e.g.: acesso com acolhimento, atenção integral e equânime com responsabilização e criação de vínculos, valorização dos trabalhadores e usuários, gestão democrática e participação social) e das medidas adotadas pela Secretaria Estadual de Saúde do Acre (SESAcre), os autores destacam o papel relevante de iniciativas atuais tomadas pela SEMSA, tais como: realização da formação de apoiadores (gestores, trabalhadores e usuários), no período entre 2011 e 2012, com o intuito de fortalecer a PNH e apoio ao III Encontro de Humanização de Coordenações Estaduais e de Capitais da Região Norte, realizado em maio de 2012, tendo em vista a reaproximação entre trabalhadores e gestores; sem contar a realização do Curso de Desenvolvimento Gerencial do SUS (CDG-SUS), objeto de análise central do livro, e sobre o qual discorreremos nos parágrafos subsequentes.

Abrindo a terceira e última parte do livro, o texto "Desenvolvimento gerencial como práxis de educação permanente: construindo agendas e coletivos de saúde”, assinado por Sonia Maria de Souza Correa e Julio S. Müller Neto, faz um recorte de um estudo de caso (entrevistas e análise documental) referente ao CDGSUS levado a cabo em São Félix do Araguaia, Mato Grosso, em 2012, tendo como objetivo averiguar o grau de correspondência entre as ações propostas pela Agenda de Fortalecimento Gerencial e sua implementação através da Programação Anual de Saúde do ano subsequente. Integrando um projeto de ensino-pesquisa e extensão desenvolvido pelo Núcleo de Desenvolvimento em Saúde do Instituto de Saúde Coletiva da Universidade Federal de Mato Grosso (NDS/ISC/UFMT), que possui como horizonte temático as demandas de saúde do usuário, a integralidade e o direito à saúde, o CDG-SUS conta com a parceria do Conselho de Secretários Municipais de Saúde do Mato Grosso (COSEMSMT) e cooperação teórico-metodológica do LAPPIS/IMS-UERJ. Os autores do estudo evidenciaram que, das 18 prioridades de ações estratégicas de planejamento elencadas pelo Plano Municipal de Saúde para 2011, nove constavam na Agenda de Fortalecimento Gerencial elaborada pelos participantes durante o curso, o que comprova sua relevância. Além disso, eles sublinharam o fato de que, não obstante a persistência dos desafios que precisam ser vencidos, a maioria dos participantes do estudo destacou a relativa melhoria na prática e no atendimento aos usuários após a realização do curso. 
No antepenúltimo capítulo do livro - "Educação Permanente no cenário da Estratégia de Saúde da Família no município de Rio Branco" -, Amanda Caroline Maciel Amorim, Alderlândia da Silva Maciel e Rosana Aparecida Salvador Rossit desenvolveram um estudo de caso envolvendo 127 profissionais de saúde e dez gestores da Atenção Básica de 19 unidades de Saúde da Família. Lançando mão de entrevistas e questionários, os autores obtiveram como um de seus principais resultados o dado de acordo com o qual profissionais e gestores veem importância na educação permanente para suas respectivas qualificações e melhorias no atendimento, bem como a percebem, em alguns casos, como uma ferramenta de educação popular. Eles concluem defendendo a tese de acordo com a qual os profissionais e gestores deveriam perceber que a política de educação permanente é fundamental, não apenas para sua qualificação profissional e pessoal, mas também, e principalmente, como mediação transformadora das práticas de cuidado, gestão e participação popular, graças ao emprego de suas metodologias ativas.

Osvaldo Leal, Rodrigo Silveira, Juliana Lofego, Elisama Lima e Emelyn Daniela Amorim começam a tratar da experiência do CDG-SUS em Rio Branco propriamente dita, como indica o título do texto "CDG-SUS Rio Branco: uma experiência compartilhada de educação permanente centrada na gestão do cuidado em saúde" (segundo capítulo da segunda parte). Por intermédio de um Núcleo Gestor local (composto por representantes do LAPPIS e da SEMSA), adaptou-se o material didático à realidade local, selecionaram-se os tutores e, por fim, escolheram-se os participantes (processo este que exigiu ampla discussão, dada a proposta de incluir nas turmas a participação, não apenas de gestores e profissionais do serviço, como também os representantes dos próprios usuários). Valendo-se do ideário de uma pedagogia dialógica inspirada em Paulo Freire, vários princípios nortearam o processo de ensino-aprendizagem durante o curso: resgate da história do SUS, centralidade no usuário e construção de uma agenda de trabalho etc. Graças ao emprego de metodologias ativas (especialmente, mosaico e memória viva), houve momentos de grande emoção durante o curso, quando os participantes rememoravam sua história pessoal com a luta coletiva em prol da saúde, o que contribuiu para a renovação do sentimento de pertença dos participantes em relação ao SUS.

Em termos de resultados mais palpáveis, quiçá a grande novidade do curso consiste na apresentação - feita pelos representantes das respectivas 
turmas - de uma agenda de trabalho endereçada ao Secretário Municipal

de Saúde e à Presidente do Conselho Municipal de Saúde, que assinam entre si um termo de compromisso relativo à implementação das açóes enumeradas na referida agenda. No balanço final dos autores: "O curso gerou um movimento intenso no SUS em Rio Branco, devido à sua potência transformadora para um novo agir ético-político de cada pessoa envolvida no processo. De fato, as práticas em saúde em nosso município tiveram um 'antes e depois' do CDG-SUS” (p. 147) Também comungando de uma avaliação positiva acerca da experiência, no capítulo "Tutoria no CDGSUS: exercitando metodologias ativas com os atores do SUS" (terceiro texto da segunda parte), Valéria Matos, Valgerlângela Silva, Érica Faria, Douglas Angel, Analdemyra Moreira, Amanda Amorim e Adônidas Rodrigues Jr. discorrem sobre o modo enriquecedor como os tutores interagiram com os profissionais da ponta, gestores e usuários, com base na observação direta dos próprios autores, bem como no relato de alguns tutores.

Do exposto sobre CDG-SUS, pode-se afirmar que é uma bela iniciativa que incorpora o espírito de duas tradições filosóficas, sem precisar explicitá-lo na letra dos escritos, a saber: o princípio da formação integral do ser humano apregoado pelos idealistas do século XVIII e o da práxis como transformação da realidade social defendido e encarnado pelos materialistas histórico-dialéticos.

Mobilizados pelo princípio da devolutiva, abriu-se espaço para uma espécie de avaliação da avaliação, em que os participantes do curso tiveram a oportunidade de tecer ponderações a seu respeito. Com efeito, no antepenúltimo capítulo da segunda parte - "Avaliação do CDG-SUS Rio Branco: a devolutiva dos participantes" -, Douglas J. Angel, Eufrasia Cadorin, Domisy Vieira Anute, Rodrigo Silveira e Hignês Sena divulgaram os principais resultados de uma pesquisa quantitativa feita com os próprios participantes do curso, na qual eles deveriam avaliar o conteúdo, a metodologia, o material didático, a atuação dos tutores, a estrutura física, os recursos audiovisuais, a participação individual e ampliação do conhecimento do SUS. Sem entrar nos pormenores, o fato é que, tendo sido considerado como base o indicador "muito bom", o curso em geral foi muito bem avaliado pelos participantes. $\mathrm{Na}$ avaliação final dos autores do texto, "[a] vivência no curso possibilitou o olhar sobre os processos de trabalho, promovendo a reflexão sobre práticas de cuidado que reafirmaram valores éticos 
e políticos, tendo como princípio as necessidades de saúde da população na perspectiva da integralidade da atenção e do direito à saúde" (p. 218).

No capítulo seguinte, intitulado "Renovação, compromisso e necessidade de diálogo: a avaliação do curso nos relatos dos participantes", Rodrigo Silveira, Valeria Matos, Valgerlângela Souza, Jauane Vilela e Suziany Dantas também divulgam os principais resultados das percepções dos próprios participantes do curso, sendo que pelo prisma qualitativo e considerando quatro eixos de análise: 1- impressões gerais e sobre o processo de aprendizado do grupo (destaque para a fala em torno do "caráter revitalizador do curso"); 2- sucessos e percalços na execução do curso (apesar das queixas relativas ao horário e à jornada de trabalho, os participantes ressaltaram vários aspectos positivos, como, por exemplo, a metodologia ativa empregada e o desempenho dos tutores); 3- transformaçôes no próprio trabalho (pontuou-se especialmente a "perspectiva da inclusão e do diálogo no planejamento das ações e na construção dos processos de trabalho, tanto no âmbito da gestão como da atenção"); 4- mudanças na maneira de agir dos participantes (na fala de um dos participantes: "muitas vezes estava me sentindo retraído e coagido, mas agora aprendi que eu sou o porta-voz do SUS”).

Um dos pontos mais altos do livro consiste na temática referente à participação social. Como diria Boaventura de Sousa Santos, está em jogo aqui a questão da democratização da própria democracia. Elisama Lima, Rosimara Werner, Verônica Loureiro e Selma Neves, no capítulo "Participação social no Acre e em Rio Branco" (último da segunda parte), descrevem os marcos históricos acerca da participação social e dos movimentos sociais no Acre e em Rio Branco. Os autores realçam o papel desempenhado, por um lado, pelos Conselhos Gestores das Unidades de Saúde, criados em 2007, responsáveis pela constituição de novos espaços públicos de participação cidadã; por outro, pelo Central de Articulação das Entidades de Saúde (CADES), criado em 2003, que vem apoiando ativamente várias ações em prol da saúde pública, notadamente as feiras de saúde.

A despeito do oportuno surgimento desses órgãos, verifica-se que a participação popular nos rumos da saúde ainda é relativamente pequena, principalmente quando comparada com o papel protagonista desempenhado pela indústria. Daí a importância da conclamação feita pelos autores nas suas últimas considerações:

O SUS, como conquista social e marco da reforma sanitária brasileira, precisa ser defendido e reafirmado na luta diária dos movimentos sociais. A acirrada disputa entre os que defendem o aperfeiçoamento do SUS entendendo-o como um direito 
de cidadania e uma das significativas conquistas sociais - senão a maior - do povo

brasileiro e os que o consideram falido e defendem a progressiva privatização da saúde com base na lógica mercadológica representada por planos e seguros de saúde, está na ordem do dia do debate técnico-político (p. 246).

No quarto capítulo da segunda parte ("Agenda em redes: construindo planejamento participativo responsável”), Rodrigo Silveira, Domisy Vieira Anute, Hignês Sena, Tuianne Caimboim Morais e Emelym Daniela Tonelly tratam especificamente do Modelo das Redes Explicativas (ferramenta empregada pelo planejamento estratégico que parte da definição de um problema, procurando conhecer suas causas e propor soluções) contidas na Agenda de Fortalecimento Gerencial do CDG-SUS Rio Branco.

Da grande quantidade de material coletado, identificaram-se cinco categorias centrais de análise, cada uma das quais se subdividindo em vários problemas e soluções correspondentes: 1- necessidade de valorização do trabalho e do trabalhador; 2- adequação dos serviços às necessidades da população; 3aproximação entre gestores, trabalhadores e usuários; 4- efetivação da participação dos usuários no controle social; 5- integração entre os níveis do sistema de saúde. $\mathrm{Na}$ avaliação dos autores, a participação de atores diversos na construção do SUS se faz necessária:

A análise das redes explicativas da Agenda de Fortalecimento Gerencial do SUS em Rio Branco construída por 242 atores, entre gestores, trabalhadores, usuários, estudantes e professores, com auxílio dos dez tutores do CDG-SUS permite que se evidencie um caminho para a consolidação e aumento da qualidade do SUS local. Esse caminho aponta para a importância da comunicação e da integração em vários níveis, no processo de trabalho das equipes, na comunicação entre as mesmas, no contato entre gestores, trabalhadores e usuários, e entre os serviços de saúde. Essa integração se faz necessária com participação de diferentes atores nos processos de planejamento, execução e avaliação das ações de saúde. (p. 176).

Por fim, e quiçá mais importante, gostaria de sublinhar o tema adstrito à gestão, notadamente a questão do apoio à gestão que dá título ao livro. Sem querer jogar com as palavras, é como se aqui ficasse patente que o livro consiste no relato de uma experiência responsável por gestar uma nova gestão. De fato, "O apoio institucional: mediação social na atenção primária à saúde”, de Mirna Teixeira e Angela Casanova, é o capítulo que fecha o livro com aquele que me parece ser seu objeto central: justamente o do apoio entendido como a arte da composição de acordos e da reflexão crítica e da ação construtiva, mesmo que, nas práticas 
concretas, esse papel ainda não esteja claramente delimitado. Tomando como fundamentação os trabalhos realizados no âmbito do LAPPIS, as autoras refletem sobre a referida temática sob a ótica do conceito de mediação social, tendo em vista assegurar a prática da integralidade na sua tríplice significação institucional, relacional e técnico-política. Pensado no contexto da $\mathrm{PNH}$, defende-se o apoio institucional como um instrumento imprescindível para uma nova cogestão na saúde, que incorpore princípios e diretrizes para uma mudança efetiva no setor, a começar pela tríplice inclusão de gestores, profissionais e usuários nos caminhos da gestão, pela gestão colegiada e participativa, pela superação da dicotomia entre gestão e cuidado, pela ampliação da clínica além do modelo biomédico, pela valorização dos trabalhadores e pela primazia da perspectiva dos usuários.

No capítulo "As ações da Secretaria Municipal de Saúde de Rio Branco a partir das redes explicativas do CDG-SUS" (quinto da segunda parte), Eufrasia Cadorin, Érica Faria, Valgerlângela Sousa, Analdemyra Moreira e Thâmires Albuquerque averiguaram, provando a proficuidade do apoio e da parceria institucional, quais estratégias propostas nas redes explicativas durante o CDGSUS foram incorporadas pela gestão da SAMSA, e os resultados são animadores: 1- revisão do Plano de Cargos, Carreira e Remuneração (PCCR) em negociação coletiva com os sindicatos; 2- revigoramento do coletivo de $\mathrm{PNH}$, com a inclusão de novos atores (e.g.: fortalecimento do fórum de saúde mental); 3criação da estratégia de Apoio Institucional; 4- reafirmação da relevância dos Conselhos Populares de Saúde (COPS) e das Feiras de Saúde. Tais iniciativas levaram os autores a reafirmarem a importância do CDG-SUS: A potência e a riqueza do CDG-SUS são a inclusão dos participantes na roda, reafirmando que é possível superar modelos burocráticos que excluem os diversos atores da gestão e da atenção. É necessário possibilitar espaços de compartilhamento e responsabilização, avançando na gestão democrática e participativa, com a transversalização das relações da gestão e atenção" (p. 188).

No momento histórico em que vivemos no Brasil, no qual se começa a alardear, de modo irresponsável, que o principal "sonho de consumo" da chamada nova classe C é possuir um plano de saúde privado, as experiências inovadoras registradas nesse livro servem como um alento para aqueles que, como eu, começaram a se sentir no direito de sonhar o novo de novo: após um longo e tenebroso período de predomínio de ordem mundial neoliberal, podemos voltar a acreditar que outro 
mundo é, não apenas possível, mas necessário e inevitável. No caso específico da saúde, malgrado o discurso derrotista de alguns que só conseguem enxergar males porque não olham além do local em que estão inseridos, em vários lugares do país estão ocorrendo experiências positivas que poderiam funcionar como fonte de inspiração para outras pessoas e instituiçôes, especialmente nos lugares ditos "periféricos" (quiçá um novo norte para a saúde venha do Norte do Brasil, como é o caso de Rio Branco). Basta unir, como disse Gramsci, o pessimismo da razão com o otimismo da ação, tendo em vista a luta por um SUS que personifique os ideais emancipatórios, universalistas, solidários e igualitários.

O livro que acabo de resenhar me motiva a querer juntar a capacidade críticoreflexiva que minha formação em filosofia me proporcionou com a ação mais concreta junto aos demais setores da sociedade que não apenas a academia. A meu juízo, foi essa, aliás, a principal fonte de sucesso da Reforma Sanitária: a luta coletiva e solidária entre acadêmicos, profissionais, movimentos sociais, estudantes e partidos. Reforma essa que continua sendo levada adiante por intermédio de um SUS que permanece pulsando firme e forte no vigor de um coração com 25 anos de existência e que há de bater cada vez mais forte e acelerado em sintonia com o novo tempo que vislumbro despontar no horizonte. 